\title{
The Mediating Role of Positive and Negative Affects in the Relationship Between Self-Esteem and Happiness
}

This article was published in the following Dove Press journal: Psychology Research and Behavior Management

\author{
Carlos Salavera $\mathbb{D}^{1,2}$ \\ Pablo Usán ${ }^{1,2}$ \\ Pilar Teruel ${ }^{1,2}$ \\ 'Research Group OPIICS, University of \\ Zaragoza, Zaragoza, Spain; ${ }^{2}$ Faculty of \\ Education, University of Zaragoza, \\ Zaragoza, Spain
}

Background: Affects, both positive and negative, can act as mediators between self-esteem and happiness. The present study is undertaken among 812 university students in order to examine the relationship between these variables.

Methods: The sample included 812 university students - 361 men (44.46\%) and 451 women (55.54\%) - who participated voluntarily. The Positive and Negative Affect Scale, Subjective Happiness Scale and Self-Esteem Scale were the instruments used in this study. Results: The results revealed that men have greater self-esteem and positive affects, while women scored higher in terms of subjective happiness. The analysis revealed a significant correlation between the variables under analysis. Positive affects show a strong positive correlation between self-esteem and happiness, while negative affects show a negative correlation. Mediation analysis suggests that affects, both positive and negative, mediate the relationship between self-esteem and subjective happiness. The results of this study may present us with new perspectives concerning the role that affects play between self-esteem and happiness.

Conclusion: The data present evidence of the mediating role-played by affects, both positive and negative, in the relationship between self-esteem and happiness. More research is needed to examine to what extent these results can be extrapolated, and how to design measures to improve psychological health and well-being.

Keywords: positive affects, negative affects, self-esteem, happiness, mediation

Self-esteem is defined as the way we value ourselves. It can thus be defined as a multidimensional construct constituted by cognitive, biological, emotional, social and behavioural factors in interaction with environmental variables and the person's perception of these factors. ${ }^{1}$ It can be defined as the subject's evaluative selfperception, and it has important emotional implications with regard to the way subject's value themselves. ${ }^{2}$ Self-esteem is one of most important functions in terms of personality, behaviour, motivation and personal development. ${ }^{3}$ While some studies point out the importance of genetics, others argue that self-esteem is a result of actions and affects, which develop throughout the life of the individual. $^{4,5}$

On the other hand, happiness is an emotional state which is satisfactory for the person. It is the sum of positive activities and emotions. Studies on happiness indicate that happy people are successful in different life spheres, such as romantic relationships, friendship, work and health. ${ }^{6}$ Those who perceive themselves as
Correspondence: Carlos Salavera Faculty of Education, University of Zaragoza, c/Pedro Cerbuna, 12, Zaragoza 50009, Spain

Email salavera@unizar.es 
happy adapt better to everyday experiences, improving their decision-making and perceiving and interpreting social conditions and stressful situations in a more positive light. ${ }^{6,7}$ People are happy when they meet their ends and frustrated when they do not, the latter leading to a loss of happiness. Happiness is a construct constituted by multiple variables, both internal and external, and different studies have pointed out its relationship with self-esteem. ${ }^{8,9}$ Furthermore, the way a person live and express his/her happiness and emotion can be mediated by their personality, which can be defined as a series of individual characteristics and differences that distinguish one person from another. $^{7}$ Thereby, the age of university students is very important in the way the adult personality is established and configured and the happiness, in the same way as the degree of personal self-esteem of each student which they can cause a normalized development or, on the other hand, can lead to problems or disorders of self-esteem and happiness of the university students which can even lead to leave or give up their studies. ${ }^{8}$

Finally, affects have been defined according to two orthogonal frameworks, positive and negative, a bipolarity between positive and negative affects which has an hereditary base, ${ }^{10}$ while positive affects occupy the field of pleasant emotions (motivation, energy, desire for affiliation, achievement or success), negative affects represent unease and unpleasant emotions (fear, inhibition, insecurity, frustration and failure). ${ }^{11,12}$ Thus, someone with highly positive affects is used to experiencing feelings of satisfaction, enthusiasm, energy, friendship, union, affirmation and confidence. They are related with extroversion, optimism and resilience behaviours. Someone with highly negative affects tends to experience lack of interest, boredom, sadness, guilt, embarrassment and envy. They can also feel temperamental sensitivity to negative stimuli: vegetative lability, stressors and unfavorable atmospheres. ${ }^{11,12}$

The dimension of positive affects is strongly correlated with that of the hedonic and allows the person to feel alert and engaged, emotions which they enjoy, while negative affects are correlated with psychophysiological distress. In short, affective states are natural responses to wins and losses throughout life.

According to the literature, self-esteem is a primary component of happiness, and can be used to predict it. ${ }^{13-16}$ Besides, some authors have suggested that affects play an important role in interpersonal relations, and that they can be linked to individual self-esteem and happiness. ${ }^{17-19}$ It has been shown that affects are used as a confrontation strategy to control emotions ${ }^{12}$ and his relationship with personality. $^{20,21}$ In this way, we should consider the possibility of evaluating the importance of affects, both positive and negative, as mediators of the relationship between selfesteem and happiness.

Therefore, this research will contribute to the scientific literature the role and influence of positive and negative affects on their mediation with the relationship between self-esteem and happiness in university students, with hardly any studies investigating them.

Consequently, our research aimed to analyse the relationship between self-esteem and happiness, and the mediating effect that affects (both positive and negative) could have in this relationship.

Hypothesis 1: The level of self-esteem has an effect on the level of emotional happiness.

Hypothesis 2: Positive and negative affects mediate the relationship between self-esteem and happiness.

\section{Method}

\section{Participants}

The sample includes 812 university students - 361 men (44.46\%) and 451 women (55.54\%) - who participated voluntarily. All of them signed a document of informed consent, and the ethical considerations put forward by the Declaration of Helsinki were observed. Results were analysed anonymously. The age of participants was between 18 and 40, with an average age of 20.73 (s.d. = 3.811).

\section{Instruments \\ PANAS Questionnaire "I}

The Positive and Negative Affect Scale (PANAS) includes 20 items, 10 of which refer to Positive Affects (PA) and the other 10 to Negative Affects (NA), distributed in two Likert scales. The values refer to the time when the survey was carried out and go from 0 (absence of the emotion) to 5 (frequent presence of the emotion). The value of $\alpha$ was 0.90 for positive affects and 0.87 for negative affects.

\section{Subjective Happiness Scale 22}

This is a global measure of subjective happiness, which evaluates a molar category of wellbeing as a global psychological phenomenon. This scale goes beyond the mere addition of positive and negative emotional states and the cognitions related to these phenomena but rather consider 
the definition of happiness from the point of view of respondents. It includes 4 items in a Likert scale. In our survey, this scale presented a high degree of internal consistency, with Cronbach's $\alpha$ taking a value of 0.82 .

\section{Self-Esteem Scale ${ }^{23}$}

This questionnaire aims to explore individual self-esteem, understood as feelings of self-value and self-respect. The scale consists of 10 items framed as sentences, five of which are enunciated positively, the other five being enunciated negatively, in order to avoid acquiescence bias of 0.80 .

\section{Procedure}

Participants were given twenty minutes to fill the abovedescribed questionnaires and the informed consent form. In all cases, they were reminded that the information provided would remain anonymous and confidential. The study protocol was approved by the Ethics Review Committee of Psychology and Sociology DepartmentUniversity of Zaragoza. All questionnaires were anonymous and participants were voluntary. The data were collected between April and May 2019.

The statistical analysis of the data was carried out with software SPSS v.26.0. After performing normal distribution and equality of variances tests, we decided to use parametric techniques. Each variable was subject to descriptive analysis. In all cases, we used the lowest signification level possible. Bilateral contrasts were undertaken. For two-group hypothesis testing, we used Students' $t$ distribution. Finally, mediation analyses were undertaken to test whether the relationship between selfesteem and happiness is mediated by positive and negative affects, following the method proposed by Baron and Kenny. ${ }^{24}$ This is an analysis strategy for testing mediation hypotheses. In this method for mediation, there are two paths to the dependent variable. The independent variable (a) must predict the dependent variable (b), and the independent variable must predict the mediator (c). Mediation is tested through three regressions: 1) Independent variable predicting the dependent variable; 2) Independent variable predicting the mediator; and 3) Independent variable and mediator predicting the dependent variable.

Calculations were performed in order to determine the potency of sample size for the mediation model used, following the guidelines offset out by Schoemann et al. ${ }^{25}$ The analyses ${ }^{26}$ indicated that, to obtain a power of 0.80 , a sample of 202 participants are needed for positive affects and 79 for negative affects. However, since the research presented in this paper was part of a broader study, we decided to work with the whole sample, which was powerful enough to detect the expected effects.

\section{Results}

Small gender differences were found in terms of selfesteem and happiness (Table 1), and it was concluded that gender influences positive affects, self-esteem and happiness, but not negative ones.

The results show that men get slightly higher scores in self-esteem and positive affects, whereas women score higher in subjective happiness. Concerning negative affects both groups yielded similar results.

Partial correlations between the self-esteem, subjective happiness, and positive and negative affects are presented in Table 2.

Positive affects were positively correlated to selfesteem $\left(\mathrm{r}=0.506^{* *}\right)$ and happiness $\left(\mathrm{r}=0.454^{* *}\right)$, while negative affects were negatively correlated with happiness $\left(\mathrm{r}=-0.537^{* *}\right)$ and self-esteem $\left(\mathrm{r}=-0.523^{* *}\right)$. Self-esteem and happiness show a strong correlation coefficient $\left(\mathrm{r}=0.647^{* *}\right)$, whereas positive and negative affects are negatively correlated $\left(\mathrm{r}=-0.255^{* *}\right)$.

In addition, a cluster analysis was performed (Table 3 ), a multivariate technique the main purpose of which is to group objects with a high degree of internal homogeneity and external heterogeneity. The idea was to detect patterns around self-esteem, happiness and positive and negative affects, taking gender into consideration; the results

Table I Results by Gender in Self-Esteem, Happiness and Affects

\begin{tabular}{|l|l|l|l|l|l|}
\hline & \multicolumn{2}{l|}{ Men } & \multicolumn{2}{l|}{ Women } & \multirow{2}{*}{ Cohen's d } \\
\cline { 2 - 5 } & x & sd & x & sd & \\
\hline Self-esteem & 31.77 & 5.52 & 30.83 & 6.10 & 0.161 \\
Subjective happiness & 19.74 & 4.38 & 21.06 & 4.81 & -0.286 \\
Positive affects & 33.15 & 5.80 & 32.33 & 6.30 & 0.153 \\
Negative affects & 22.65 & 7.41 & 22.90 & 8.10 & -0.032 \\
\hline
\end{tabular}

Table 2 Correlations Between Self-Esteem, Happiness and Affects

\begin{tabular}{|l|l|l|l|}
\hline & Self-Esteem & Happiness & Positive Affects \\
\hline Happiness & $0.647^{* *}$ & & \\
Positive affects & $0.506^{* *}$ & $0.454^{* *}$ & \\
Negative affects & $-0.523^{* *}$ & $-0.537^{* *}$ & $-0.255^{* *}$ \\
\hline
\end{tabular}

Note: $* * p<0.01$. 
Table 3 Self-Esteem, Happiness and Positive and Negative Affects Cluster

\begin{tabular}{|c|c|c|c|c|c|c|c|c|}
\hline & \multicolumn{4}{|c|}{$\operatorname{Men}(\mathrm{N}=361)$} & \multicolumn{4}{|c|}{ Women $(\mathrm{N}=45 \mathrm{I})$} \\
\hline & I & 2 & 3 & $\mathbf{x}$ & $\mathbf{I}$ & 2 & 3 & $\mathbf{x}$ \\
\hline Self-esteem & 34.18 & 24.25 & 32.73 & 31.77 & 35.44 & 24.32 & 30.42 & 30.83 \\
\hline Subjective happiness & 21.71 & 16.25 & 19.48 & 19.74 & 24.19 & 16.12 & 21.20 & 21.06 \\
\hline Positive affects & 32.35 & 26.13 & 36.65 & 33.15 & 37.55 & 29.20 & $28.6 I$ & 32.33 \\
\hline Negative affects & 16.12 & 35.63 & 23.02 & 22.65 & 19.13 & 33.48 & 19.16 & 22.90 \\
\hline \multirow[t]{2}{*}{ N (\%) } & 137 & 63 & 161 & & 179 & 119 & 153 & \\
\hline & (37.95) & $(17.45)$ & (44.59) & & (39.69) & (26.39) & (33.92) & \\
\hline
\end{tabular}

yielded three groups per gender. Concerning men, the three groups were as follows: 1) 137 respondents (37.95\%), with self-esteem and subjective happiness above average, positive affects near average, and below average negative affects; 2) 63 respondents (17.45\%), with self-esteem, happiness and positive affects below average and high values for negative affects; and 3) 161 participants $(44.59 \%)$, with self-esteem, happiness and negative affects near average, but positive affects slightly above average. Concerning women, the three groups were as follows: 1) 179 participants (39.69\%), with self-esteem, happiness and positive affects above average and negative affects below average; 2) 119 respondents (26.39\%), with very low scores in terms of self-esteem, happiness and positive affects, and very high values of negative affects; and 3) 153 respondents (33.92\%), with self-esteem and happiness near average, but negative and positive affects below average. Although groups were fairly homogenous in terms of gender, some differences were detected in groups 2 and 3; in group 1 men and women yielded similar results. The percentage of men in the second group (below average self-esteem, happiness and positive affects) was $9 \%$ below women. In the third group, women yielded lower values in terms of both positive and negative affects.

In order to assess whether the relationship between self-esteem and happiness is mediated by positive and negative affects, mediation analyses were undertaken following Baron and Kenny. ${ }^{24}$ After ensuring that our survey met all the requisites established by these authors, the macro Process 3.0 from SPSS (version 26.0) developed by $\mathrm{Hayes}^{27}$ was used. The mediation analysis took into consideration sex and age, and neither variable was shown to have a significant impact in the relationship between self-esteem and happiness.

In order to test the statistical significance of mediation, bootstrapping (10,000 runs) and Sobel's test were undertaken. Both tests showed that both positive and negative affects mediate the relationship between self-esteem and happiness. The results indicated an effect of self-esteem (VI) on affects as a mediating variable (VM), 0.52 for positive affects (PA) and -0.69 for negative affects, (NA), $\mathrm{p}<0.001$ in both cases. Also, the impact of affects on happiness (VD) was 0.13 for AP and -0.16 for NA, $\mathrm{p}<0.001$ in both cases. Zero was not included in the bootstrap interval, CI 95\% [0.001-0.002], and Sobel's test also indicated that the value of $\mathrm{c}$ is statistically significant $(\mathrm{z}=$ $2.82 ; \mathrm{p}=0.005)$; as a result, we may say that there is total mediation (Figure 1).

According to our hypothesis, self-esteem has a direct positive effect on happiness of $0.32(\mathrm{p}<0.001)$, with a total effect (direct + indirect effects) mediated by positive and negative affects of $0.51(\mathrm{p}<0.001)$, suggesting that positive and negative affects directly mediated the relationship between self-esteem and happiness. The proportion of variance for happiness as explained by the model was $R^{2}=0.64$.

\section{Discussion and Conclusions}

The present survey analysed the influence of self-esteem on happiness, evaluating the potential mediation effect of affects, both positive and negative, in this relationship. The survey also presents some descriptive data on self-esteem, subjective happiness and affects. Results show that men score better in terms of self-esteem, happiness and affect, which agrees with recent studies that suggest that men have a greater ability to recognise and regulate their emotions. ${ }^{28,29}$ These results may be related to men's tendency to agree with positive self-statements, reflecting unconscious dispositions towards the self. ${ }^{30}$ Women, however, scored better in terms of subjective happiness, in contrast with recent studies that did not detect significant gender differences in this variable, ${ }^{31}$ which confirms how difficult it is to reach conclusive results in this field. ${ }^{32}$ Therefore, we must conclude that not enough studies 


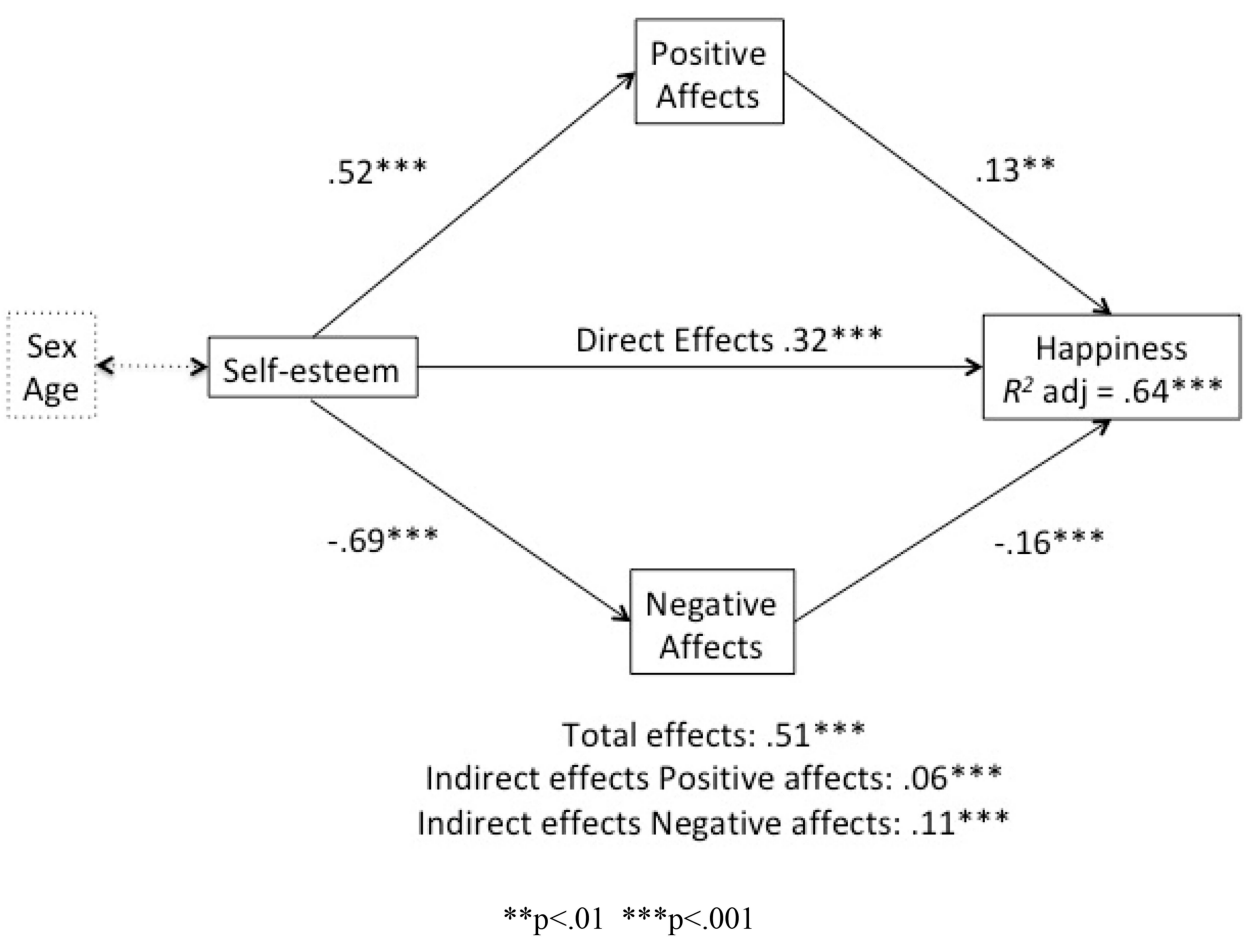

Figure I Mediation model for the effect of positive and negative affects in the relationship between self-esteem and happiness, by sex and age. $* * p<0.0$ I $* * * p<0.00$ I.

exist to reach firm conclusions concerning the effect of gender on the variables under study.

In any case, following the proposals put forward by Vantieghem et $\mathrm{al}^{33}$ and developed by others, ${ }^{34,35}$ which recommend working from the perspective of gender identity theory and that suggest that gender identity may be linked to some emotional and affective behaviours, it may prove a fruitful option to investigate the relationship between gender identity, self-esteem, happiness and affects.

In this study, the cluster analysis took gender into consideration, leading to the emergence of three groups: one in which self-esteem and subjective happiness was above average, positive affects were near average, and negative affects were below average; one in which self-esteem, happiness and negative affects were near average, but positive affects were slightly above average; and finally, one in which self-esteem, happiness and positive affects were below average, and negative affects yielded high scores. These results suggest that affects are correlated with selfesteem and subjective happiness, and further, that they indicate that one in six men and one in four women show low self-esteem, low subjective happiness values, underused positive affects and overused negative affects. Since this was not a clinical study, these results are concerning, because an adequate use of affects and robust self-esteem and happiness can be an important emotional support and a valuable tool for conflict resolution. ${ }^{36-38}$

Our second aim was to analyse the potential mediating effect of affects (positive and negative) in the relationship between self-esteem and happiness. The value of selfesteem to predict happiness was demonstrated, as was the mediating role of positive and negative affects. Self-esteem has been shown to have an effect on positive affects, which in turn, had a positive impact upon the happiness of participants. Since affects are an emotion-regulating tool, ${ }^{39,40}$ these results indicate that positive affects can be an indicator of the degree to which a person feels active, alert, energetic and enthusiastic. ${ }^{41}$ In addition to this, selfesteem was shown to have an effect on negative affects, which in turn have an effect on happiness, probably because negative affects denote the opposite emotional states: upset, wrath, guilt, fear and nervousness. ${ }^{12}$

These results agree with the idea that people with a high degree of positive affects tend to experience satisfaction, energy, enthusiasm, engagement, friendship, selfaffirmation and self-confidence, whereas people with a high degree of negative affects will tend to experience lack of interest, sadness, boredom, shame, guilt and envy, all of which are directly linked with self-esteem and subjective happiness. $^{21,42,43}$ 


\section{Study Limitations}

The limitations of this study must be taken into account in the interpretation of results. Although the sample is statistically significant, it should be expanded to other population groups, including clinical groups, where the association between these constructs - affects, self-esteem, happiness may be stronger still. It is also desirable to carry out studies with a temporal dimension, in order to reveal the evolution of affects, as well as their relationship with self-esteem and happiness over a longer time period.

\section{Future Prospects}

As future perspectives, it would be interesting to investigate the positive and negative effects and their impact on other psychological variables. Similarly, it might be interesting to use longitudinal models to assess the evolution of conditions over time in university students, as well as to extend the sample to other educational stages, such as primary or secondary education in adolescents.

\section{Practical Implications}

The practical implications derived from this research can lead strategic strategies that improve the self-esteem and happiness of university students by teachers addressing self-determined variables such as motivation, effort and commitment.

In addition, intervention programs to work with adolescents in the variables can contribute to the integral formation of students, and reduce school failure at the University.

In conclusion, it can be argued that self-esteem acts as a predictor of happiness and that affects play a mediating role in that relationship. It was also concluded that greater self-esteem leads to greater expression of positive affects and to the reduction of negative affects. In turn, positive affects result in greater happiness, while negative affects lead to less happiness. The results of this study allow us to demonstrate the predictive role of self-esteem in happiness and the mediating function that both positive and negative affects play between self-esteem and happiness.

\section{Ethics and Consent Statement}

All procedures performed in studies involving human participants were in accordance with the ethical standards of the institutional research committee and with the 1964 Helsinki Declaration and its later amendments or comparable ethical standards.

\section{Informed Consent}

Informed consent was obtained from all individual adult participants included in the study.

\section{Funding}

This study was performed by Research Group OPIICS (S46_17R), University of Zaragoza (Zaragoza, Spain) and was supported by research funds provided by the Department of Science and Technology of the Government of Aragón (Spain) and the European Social Fund.

\section{Disclosure}

The authors declare that they have no conflict of interest.

\section{References}

1. Peñaherrera M, Cachón JY, Ortiz A. La autoestima profesional docente y su implicación en el aula. Magister. 2014;26(1):52-58. doi:10.1016/S0212-6796(14)70018-0

2. Villasmil J. El autoconcepto académico en estudiantes universitarios resilientes de alto rendimiento: Un estudio de casos (tesis sin publicar). Universidad de Los Andes; 2010.

3. Tabernero C, Serrano A, Mérida R. Estudio comparativo de la autoestima en escolares de diferente nivel socioeconómico. Psicología Educativa. 2017;23(1):9-17. doi:10.1016/j.pse.2017.02.001

4. Dörr A. Estudio comparativo de autoconcepto en niños de diferente nivel socio económico (tesis sin publicar). Universidad De Chile; 2005.

5. Kendler KS, Gardner CO, Prescott CA. A population-based twin study of self-esteem and gender. Psychol Med. 1998;28 (6):1403-1409. doi:10.1017/S0033291798007508

6. Lyubomirsky S, King L, Diener E. The benefits of frequent positive affect: does happiness lead to success? Psychol Bull. 2005;131 (6):803-855. doi:10.1037/0033-2909.131.6.803

7. Salavera C, Usán P, Pérez S, Chato A, Vera S. Differences in happiness and coping with stress in secondary education students. Procedia Soc Behav Sci. 2017;237:1310-1315. doi:10.1016/j. sbspro.2017.02.215

8. Ng JCK, Cheung VWT, Lau VCY. Unpacking the differential effects of dispositional envy on happiness among adolescents and young adults: the mediated moderation role of self-esteem. Person Indiv Dif. 2019;149:244-249. doi:10.1016/j.paid.2019.06.011

9. Tan C, Krishnan SA, Lee Q. The role of self-esteem and social support in the relationship between extraversion and happiness: a serial mediation model. Curr Psychol. 2017;36(3):556-564. doi:10.1007/s12144-016-9444-0

10. Watson D, Tellegen A. Toward a consensual structure of mood. Psychol Bull. 1985;98(2):219-235. doi:10.1037/0033-2909.98.2.219

11. Longo Y. The simple structure of positive affect. Soc Indic Res. 2015;124(1):183-198. doi:10.1007/s11205-014-0776-6

12. Watson D, Clarke LA, Tellegen A. Development and validation of brief measures of positive and negative affect: the PANAS scales. J Pers Soc Psychol. 1998;54(6):1063-1070. doi:10.1037/0022-3514. 54.6.1063

13. Baumeister R, Campbell J, Krueger J, Vohs K. Does high self-esteem cause better performance, interpersonal success, happiness, or healthier lifestyles? Psychol Sci Public Interest. 2003;4(1):1-44. doi:10. $1111 / 1529-1006.01431$ 
14. Cheng H, Furnham A. Perceived parental rearing style, self-esteem and self-criticism as predictors of happiness. J Happiness Stud. 2004;5(1):1-21. doi:10.1023/B:JOHS.0000021704.35267.05

15. Diener E, Diener M. Cross-cultural correlates of life satisfaction and self-esteem. J Pers Soc Psychol. 1995;69(1):120-129. doi:10.1037/ 0022-3514.69.1.120

16. Simsek O. Structural relations of personal and collective self-esteem to subjective well-being: attachment as moderator. Soc Indic Res. 2013;110(1):219-236. doi:10.1007/s11205-011-9927-1

17. Aillaud M, Piolat A. Compréhension et appreciation de l'humour: approche cognitivo-émotionnelle. Psychol française. 2013;58 (4):255-275. doi:10.1016/j.psfr.2013.04.001

18. Moran JM, Rain M, Page-Gould E, Mar RA. Do I amuse you? Asymmetric predictors for humor appreciation and humor production. J Res Person. 2014;49:8-13. doi:10.1016/j.jrp.2013.12.002

19. Yip JA, Martin RA. Sense of humor, emotional intelligence, and social competence. J Res Person. 2006;40(6):1202-1220. doi:10.1016/j.jrp. 2005.08.005

20. Mussel P. From needs to traits: the mediating role of beliefs about control. Pers Indiv Dif. 2019;151:109525. doi:10.1016/j.paid.2019.109525

21. Salavera C, Usán P, Antoñanzas JL, Teruel P, Lucha O. Affects and personality: a study with university students. Ann Med Psychol. 2017;175:353-357. doi:10.1016/j.amp.2016.06.014

22. Lyubomirsky S, Leeper HS. A measure of subjective happiness: preliminary reliability and construct validation. Soc Indic Res. 1999;46(2):137-155. doi:10.1023/A:1006824100041

23. Rosenberg M. Society and the Adolescent Self-Image. Princeton, NJ: Princeton University Press; 1965.

24. Baron RM, Kenny DA. The moderator-mediator variable distinction in social psychological research: conceptual, strategic, and statistical considerations. J Person Soc Psychol. 1986;51(6):1173-1182. doi:10.1037/0022-3514.51.6.1173

25. Schoemann AM, Boulton AJ, Short SD. Determining power and sample size for simple and complex mediation models. Soc Psychol Pers Sci. 2017;8(4):379-386. doi:10.1177/1948550617715068

26. Cohen J. Cosas que he aprendido (hasta ahora). An Psicol. 1992;8 $(1-2): 3-17$

27. Hayes AF. Introduction to Mediation, Moderation, and Conditional Process Analysis: A Regression-Based Approach. New York, NY: Guilford Press; 2018.

28. Martínez-Marín MD, Martínez C. Subjective well-being and gender-typed attributes in adolescents: the relevance of emotional intelligence. Aust J Psychol. 2019;71(3):296-304. doi:10.1111/ajpy.12247

29. Walther M, Hilbert A. Emotional openness in overweight and normal-weight adolescents. Swiss J Psychol. 2015;71(1):29-36. doi:10.1024/1421-0185/a000145

30. Magee W, Upenieks L. Gender differences in self-esteem, unvarnished self-evaluation, future orientation, self-enhancement and self-derogation in a US national sample. Pers Indiv Dif. 2019; 149:66-77. doi:10.1016/j.paid.2019.05.016
31. Carmaichael KE, Czech DR. An examination of happiness between race, gender and school classification: an echo boomer analysis. Int J Happiness Develop. 2019;5(1):25-32. doi:10.1504/IJHD.20 19.098049

32. Gartxia L, Aritzeta A, Bulluerka NY, Barberá E. Inteligencia emocional y género: más allá de las diferencias sexuales. An Psicol. 2012;28:567-575. doi:10.6018/analesps.28.2.124111

33. Vantieghem W, Vermeersch H, Van Houtte M. Transcending the gender dichotomy in educational gender gap research: the association between gender identity and academic self-efficacy. Cont Educ Psychol. 2014;39(4):369e378. doi:10.1016/j.cedpsych.2014. 10.001

34. Hoffman AJ, Dumas F, Loose F, Smeding A, Kurtz-Costes B, Régner I. Development of gender typicality and felt pressure in European French and North African French adolescents. Child Dev. 2019;90(3):306-321. doi:10.1111/cdev.12959

35. Salavera C, Usán P, Jarie L. Emotional intelligence and social skills on self-efficacy in secondary education students. Are there gender differences? J Adol. 2017;60:39-46. doi:10.1016/j.adolescence.2017. 07.009

36. Diener E, Oishi S, Lucas RE. Personality, culture and subjective well-being: emotional and cognitive evaluations of life. Ann Rev Psychol. 2003;54(1):403-425. doi:10.1146/annurev.psych.54.101601. 145056

37. Litvinova O, Kolomoichuk D. Psychological peculiarities of behaviour strategies in intergenerational family conflicts. Sci Educ. 2016;33(2-3):138-144. doi:10.24195/2414-4665-2016-2-3-25

38. Nieslen KS, Gwozdz W, De Rider D. Unraveling the relationship between trait self-control and subjective well-being: the mediating role of four self-control strategies. Front Psychol. 2019;10:706. doi:10.3389/fpsyg.2019.00706

39. Erickson S, Feldstein S. Adolescent humor and its relationship to coping, defense strategies, psychological distress, and well-being. Child Psychiatry Hum Dev. 2007;37(3):255-271. doi:10.1007/ s10578-006-0034-5

40. Saroglou V, Scariot C. Humor style questionnaire: personality and educational correlates in Belgian high school and college students. Eur J Pers. 2002;16(1):43-54. doi:10.1002/per.430

41. Sandin B, Chorot P, Lostao L, Joiner TE, Santed MA, Valiente RM. Escalas PANAS de afecto positivo y negativo: validación factorial y convergencia transcultural. Psicothema. 1999;11:37-51.

42. Clark LA, Watson D. Tripartite model of anxiety and depression: psychometric evidence and taxonomic implications. $J$ Abnorm Psychol. 1991;100(3):316-336. doi:10.1037/0021-843X.100.3.316

43. Crawford JR, Henry JD. The Positive and Negative Affect Schedule (PANAS): construct validity, measurement properties and normative data in a large non-clinical sample. Br J Clin Psychol. 2004;43 (3):245-265. doi:10.1348/0144665031752934
Psychology Research and Behavior Management

\section{Publish your work in this journal}

Psychology Research and Behavior Management is an international, peer-reviewed, open access journal focusing on the science of psychology and its application in behavior management to develop improved outcomes in the clinical, educational, sports and business arenas. Specific topics covered in the journal include: Neuroscience, memory and decision making; Behavior modification and management; Clinica applications; Business and sports performance management; Social and developmental studies; Animal studies. The manuscript management system is completely online and includes a very quick and fair peer-review system, which is all easy to use. Visit http://www. dovepress.com/testimonials.php to read real quotes from published authors. 